\title{
RESEARCH REPORTS
}

\section{Biological}

\author{
M. Suzuki ${ }^{1}$, M. Shin ${ }^{1}$, J.P. Simmer ${ }^{2}$, \\ and J.D. Bartlett ${ }^{*}$
}

${ }^{1}$ Department of Mineralized Tissue Biology, The Forsyth Institute, Cambridge, MA, USA, and Harvard School of Dental Medicine, Boston, MA, USA; and ${ }^{2}$ Department of Biological and Material Sciences, University of Michigan School of Dentistry, Ann Arbor, MI, USA; *corresponding author, jbartlett@forsyth.org

J Dent Res 93(10):1022-1027, 2014

\section{ABSTRACT}

Dental fluorosis is caused by chronic high-level fluoride $\left(\mathrm{F}^{-}\right)$exposure during enamel development, and fluorosed enamel has a higher than normal protein content. Matrix metalloproteinase 20 cleaves enamel matrix proteins during the secretory stage, and KLK4 further cleaves these proteins during the maturation stage so that the proteins can be reabsorbed from the hardening enamel. We show that transforming growth factor $\beta 1$ (TGF- $\beta 1$ ) can induce Klk4 expression, and we examine the effect of $\mathrm{F}^{-}$on TGF- $\beta 1$ and KLK4 expression. We found that in vivo $\mathrm{F}^{-}$inhibits $K l k 4$ but not Mmp20 transcript levels. LacZ-C57BL/6$K l k 4^{+/ L a c Z}$ mice have $L a c Z$ inserted in frame at the $K l k 4$ translation initiation site so that the endogenous Klk4 promoter drives LacZ expression in the same temporal/spatial way as it does for Klk4. KLK4 protein levels in rat enamel and $\beta$-galactosidase staining in LacZ-C57BL/6-Klk4 ${ }^{+/ L a c Z}$ mouse enamel were both significantly reduced by $\mathrm{F}^{-}$ treatment. Since TGF- $\beta 1$ induces $K L K 4$ expression, we tested and found that $\mathrm{F}^{-}$significantly reduced $T g f-\beta 1$ transcript levels in rat enamel organ. These data suggest that $\mathrm{F}^{-}$-mediated downregulation of TGF- $\beta 1$ expression contributes to reduced KLK4 protein levels in fluorosed enamel and provides an explanation for why fluorosed enamel has a higher than normal protein content.

KEY WORDS: amelogenin, matrix metalloproteinases, proteases/proteinases, signal transduction, cell stress, gene expression.

\section{DOI: $10.1177 / 0022034514545629$}

Received May 21, 2014; Last revision July 8, 2014; Accepted July 10, 2014

(C) International \& American Associations for Dental Research

\section{Fluoride Affects Enamel Protein Content via TGF- $\beta 1$-mediated KLK4 Inhibition}

\section{INTRODUCTION}

Community water fluoridation is recommended by the U.S. Public Health Service because appropriate levels $(0.7 \mathrm{ppm})$ of fluoride $\left(\mathrm{F}^{-}\right)$prevent dental caries (Centers for Disease Control and Prevention, 2001). However, exposure to excessive amounts of $\mathrm{F}^{-}(>1.5 \mathrm{ppm})$ during enamel development causes dental fluorosis (Dean and Elvove, 1936). The mineral content of fluorosed enamel is reduced, and the enamel retains greater than normal protein levels. Fluorosed teeth may appear mottled, discolored, and porous and may be more susceptible to decay (DenBesten, 1999).

Enamel development occurs in stages, as defined by the morphology of the ameloblasts responsible for enamel formation. Secretory-stage ameloblasts secrete matrix metalloproteinase 20 (MMP20) and enamel proteins that combine to form a mineralization front that promotes appositional growth until the enamel layer reaches full thickness (Simmer et al., 2012; Bartlett, 2013). Maturation-stage ameloblasts secrete KLK4, reabsorb protein degradation products, and promote mass mineral deposition as the enamel hardens into its final form (Hu et al., 2007). Ameloblasts are exquisitely sensitive to environmental stress. High fever during enamel development (Tung et al., 2006) and even the process of being born (Zanolli et al., 2011) can result in enamel defects.

Previously, we proposed an "acid hypothesis" to explain why fluorosis occurs mainly during the maturation stage. The hypothesis proposes that the mass mineral precipitation of this stage creates an acid environment in which greater amounts of $\mathrm{F}^{-}$become highly toxic hydrofluoric acid. Hydrofluoric acid easily passes through the ameloblast membrane down a steep concentration gradient from the acid environment into the neutral cytosol, and this elicits an ameloblast stress response (Sharma et al., 2010). The acid hypothesis predicts that maturation-stage ameloblast cell functions are more severely affected by $\mathrm{F}^{-}$exposure than are secretory-stage cell functions. For these reasons, we chose to examine the effect of $\mathrm{F}^{-}$on kallikrein 4 (KLK4) expression.

KLK4 is a glycosylated, chymotrypsin-like serine protease that is expressed and secreted by maturation-stage ameloblasts (Simmer et al., 1998; Hu et al., 2000). KLK4 degrades enamel matrix proteins (Ryu et al., 2002) before their export from the hardening enamel (Smith et al., 2011). Ablation of Klk4 in mice results in abnormally soft enamel with a higher than normal protein content (Simmer et al., 2009), and fluorosed enamel displays the same characteristics. Previously, we showed that murine Klk4 transcript levels were reduced after $\mathrm{F}^{-}$treatment (Sharma et al., 2010), and here we propose a mechanism by which this occurs and demonstrate that protein levels are similarly affected. 


\section{MATERIALS \& METHODS}

\section{Animals}

All animals were treated humanely as approved by the Forsyth Institutional Animal Care and Use Committee. The Forsyth Institute is accredited by the Association for Assessment and Accreditation of Laboratory Animal Care International, which follows the National Research Council's Guide for the Care and

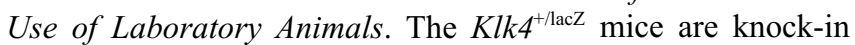
mice with $L a c Z$ inserted in frame into the Klk4 translation initiation site such that the endogenous upstream Klk4 promoter drives $L a c Z$ expression (Simmer et al., 2009). Six-week-old Sprague-Dawley rats and $K l k 4^{+/ l a c Z}$ mice were provided ad libitum water containing $\mathrm{F}^{-}(0,50$, or $100 \mathrm{ppm})$ as $\mathrm{NaF}$. After 6 wk of $\mathrm{F}^{-}$treatment, animals were euthanized, and tissues were obtained for quantitative real-time polymerase chain reaction (qPCR), Western blots, and histochemistry.

\section{Cell Culture}

Mouse ameloblast-lineage cells (ALCs; Nakata et al., 2003) were cultured at pH 7.4 in DMEM (Invitrogen, Carlsbad, CA, USA) supplemented with $10 \%$ fetal bovine serum. The human prostate carcinoma cell line (LNCaP) was purchased from ATCC (Manassas, VA, USA) because it expresses KLK4 (Xi et al., 2004). These cells were cultured at pH 7.4 in modified (ATCC) RPMI1640 medium (Invitrogen) supplemented with $10 \%$ fetal bovine serum. LNCaP cells $\left(3.0 \times 10^{5}\right.$ cells $)$ were seeded into 6-well plates and after $48 \mathrm{hr}$ were stimulated with either human recombinant transforming growth factor $\beta 1$ (TGF$\beta 1$; Sigma, St. Louis, MO, USA) or vehicle (4 mM HCL $+1 \mathrm{mg}$ / mL BSA) at the indicated concentrations. After $24 \mathrm{hr}$, total RNA was extracted. ALCs $\left(3.0 \times 10^{5}\right)$ were seeded into 6-well plates and after $24 \mathrm{hr}$ were treated with $\mathrm{F}^{-}(0,1,3$ or $5 \mathrm{mM})$ as sodium $\mathrm{F}^{-}$(Fisher Scientific, Pittsburg, PA, USA) for $24 \mathrm{hr}$, followed by total RNA extraction.

\section{qPCR Analysis}

Total RNA was extracted from LNCaP cells, ALCs, and secretory- and maturation-stage rat mandibular incisor enamel organs (EOs) via Direct-zol RNA MiniPrep (Zymo Research Corp., Irvine, CA, USA). Total RNA $(1 \mu \mathrm{g})$ was reverse transcribed into cDNA with Transcriptor First Strand cDNA Synthesis Kit (Roche Diagnostics, Minneapolis, MN, USA). The cDNA was subjected to qPCR amplification on a LightCycler 480 RealTime PCR System (Roche Diagnostics). The relative expression of target genes was determined by the $2^{-\Delta \Lambda C T}$ method (Pfaffl, 2001). For cultured cells, cDNA from 3 different samples for each treatment group was assayed 3 times in duplicate. For rat EOs, cDNA from 4 rat incisors for each treatment group was assayed in duplicate. The internal reference control gene was Eefl $\alpha 1$ because of its consistent expression with variations in $\mathrm{F}^{-}$treatment. For human recombinant TGF- $\beta 1$ experiments, $R n 18 S$ was the control gene. Primers (Invitrogen) and their sequences were as follows:
Rat EO: Klk4, forward: 5'-GCTGCTGTATGACCCCGT G-3', reverse: 5'-CCCCCAGAGTCCCCATTG-3'; Mmp20, forward: 5'-CCCACCTCACAAGCCATCC-3', reverse: 5'-CTGGTGATGGTGCTGGGCC-3'; $T g f-\beta 1$, forward: 5'-AGGACCTGGGTTGGAAGTGGAT-3', reverse: 5'-AAGCGCCCGGGTTGTGTT-3'; Eefl $\alpha 1$, forward: 5'-TGATGCCCCAGGACACAGAGACT-3', reverse: 5'-GATACCAGCTTCAAATTCCCCAACAC-3'.

Murine ALCs: $T g f-\beta 1$, forward: 5'-AGGACCTGGGTTGG AAGTGGAT-3', reverse: 5'-AAGCGCCCGGGTTGT GTT-3'; Eefl $\alpha 1$, forward: 5'-GTCGCAGGGGCTTGT CAGTT-3'.

Human LNCaP cells: KLK4, forward: 5'-CGAACGGCA GAATGCCTACC-3', reverse: 5'-CAAGGCCCTGCA AGTACCCG-3'; 18S, forward: 5'-GTAACCCGTTGA ACCCCATT-3', reverse: 5'-CCATCCAATCGGTAGT AGCG-3'.

\section{Western Blot Analysis}

Bulk secretory and maturation-stage enamel from extracted mandibular incisors was dissolved by incubation in $2 \mathrm{~mL}$ of $0.17 \mathrm{M} \mathrm{HCl} / 0.98 \%$ formic acid for $2 \mathrm{hr}$ at $4{ }^{\circ} \mathrm{C}$. Undissolved material was removed by centrifugation at $5,000 \mathrm{~g}$ for $10 \mathrm{~min}$ at $4^{\circ} \mathrm{C}$. The supernatants were neutralized by dialyzing against $50 \mathrm{mM}$ Tris- $\mathrm{HCl}$ buffer ( $\mathrm{pH}$ 7.4). For amelogenin, samples were aliquoted and lyophilized. For KLK4, samples were fractionated with $20 \%$ ammonium sulfate, and precipitates were removed by centrifugation. Supernatants were dialyzed against $0.1 \mathrm{M}$ acetic acid and lyophilized. KLK4 protein $(10 \mu \mathrm{g})$ and amelogenin protein $(1 \mu \mathrm{g})$ were used for blotting procedures with polyclonal antibodies as described previously (Yamakoshi et al., 2011).

\section{Histochemistry and X-gal Staining}

Incisors from $\mathrm{Klk}^{+/ \mathrm{LacZ}}$ mice were fixed in 5\% formalin overnight at $4^{\circ} \mathrm{C}$, followed by decalcification with $10 \%$ EDTA at $4^{\circ} \mathrm{C}$ for $2 \mathrm{wk}$. Samples were then embedded in optimal cutting temperature compound (Sakura Fineteck, Torrance, CA) and frozen at $-80^{\circ} \mathrm{C}$. Serial sagittal sections were stained with $\mathrm{X}$-gal as described previously (Simmer et al., 2011). The mean intensity of X-gal staining was quantified by use of ImageJ software (Schneider et al., 2012).

\section{Statistical Analysis}

The qPCR results and X-gal staining intensity were analyzed by 1 -way analysis of variance with Fisher's protected least significant difference post hoc test. Values of $p<.05$ were considered statistically significant.

\section{RESULTS}

\section{F- Decreases Klk4 but Not Mmp20 Expression in Rat EO}

$\mathrm{F}^{-}$treatment significantly decreased $K l k 4$ transcript levels (Fig. 1A, $p<.01)$ during the maturation stage of enamel development. 

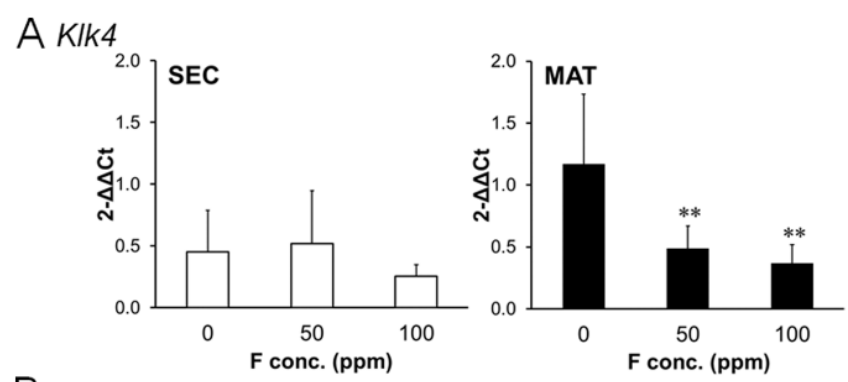

B Mmp20
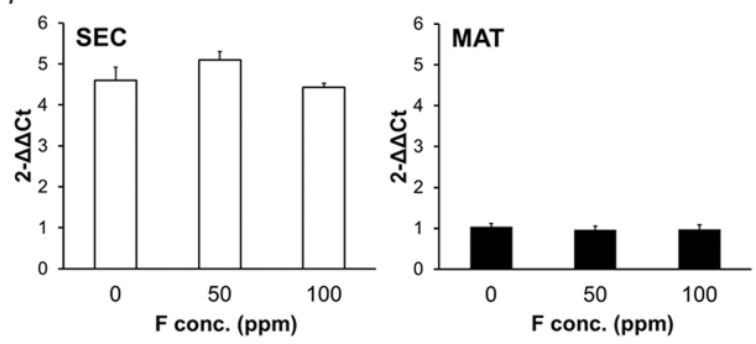

Figure 1. Fluoride decreased Klk4 gene expression in maturationstage rat enamel organ. Rats were supplied ad libitum fluoride 10,50 , or $100 \mathrm{ppm}$ ) as $\mathrm{NaF}$ in drinking water for 6 wk. Quantitative real-time polymerase chain reaction was performed on secretory-stage (SEC; left panels) and maturation-stage (MAT; right panels) enamel organs. (A) Klk4 expression and (B) Mmp20 expression were quantified by quantitative real-time polymerase chain reaction by use of the $\Delta \Delta C T$ method. Eefl 1 served as the reference gene control. cDNA from 4 rats in each treatment group were assayed in duplicate. All results were normalized to the $0 \mathrm{ppm}$ maturation-stage result of Klk4 or Mmp20 respectively. Data are expressed as mean \pm SD. ${ }^{*} p<.05$, ${ }^{* *} p<.01$, vs. 0 ppm.

Conversely, Mmp20 is expressed during the secretory stage, and $\mathrm{F}^{-}$did not significantly affect $\mathrm{Mmp} 20$ expression during this stage (Fig. 1B). The low levels of expression observed for Klk4 during the secretory stage and for Mmp20 during the maturation stage were likely due to a small overlap in the separation of these stages during the EO dissection.

\section{Decreased Quantities of KLK4 Protein Were Present in $F^{-}$-Treated Rat Incisor Enamel}

To determine if $\mathrm{F}^{-}$treatment also reduced rat enamel KLK4 protein levels, we performed immunoblots on total protein extracted from rat mandibular incisors. Compared with the $\mathrm{F}^{-}$ controls $(0 \mathrm{ppm}), \mathrm{KLK} 4$ protein levels were attenuated in the $\mathrm{F}^{-}$treatment groups (50 and 100 ppm; Fig. 2; upper panel). In contrast, amelogenin, which is expressed during the secretory stage of development, showed no obvious decrease in protein levels among $\mathrm{F}^{-}$treatment groups (Fig. 2; lower panel). These data support the acid hypothesis, postulating that the acidic environment of the maturation stage makes ameloblasts more susceptible to the toxic effects of $\mathrm{F}^{-}$exposure.

\section{LacZ Expression in Klk4+/LacZ Mice Treated with $\mathrm{F}^{-}$}

In $K l k 4^{+ \text {LacZ }}$ knock-in mice, one allele expresses Klk4 and the other expresses LacZ via the endogenous Klk4 upstream

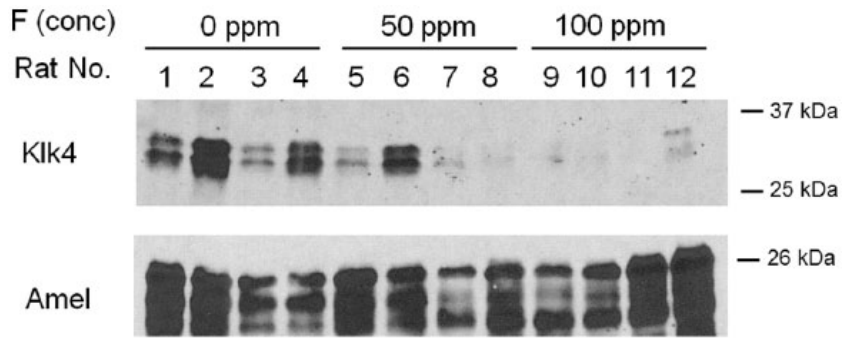

Figure 2. Fluoride attenuates KLK4 protein levels in rat incisor enamel. Rats were supplied ad libitum fluoride $(0,50$, or 100 ppm) in drinking water for 6 wk. Protein was extracted from mandibular incisor enamel and assessed by Western blot procedures by use of antibodies specific for KLK4 (upper panel) or amelogenin (lower panel). KLK4 protein levels were assessed in incisors from 4 rats per treatment group (fluoride treatment groups: 0 ppm, lanes 1-4; 50 ppm, lanes 5-8; 100 ppm, lanes 9-12)

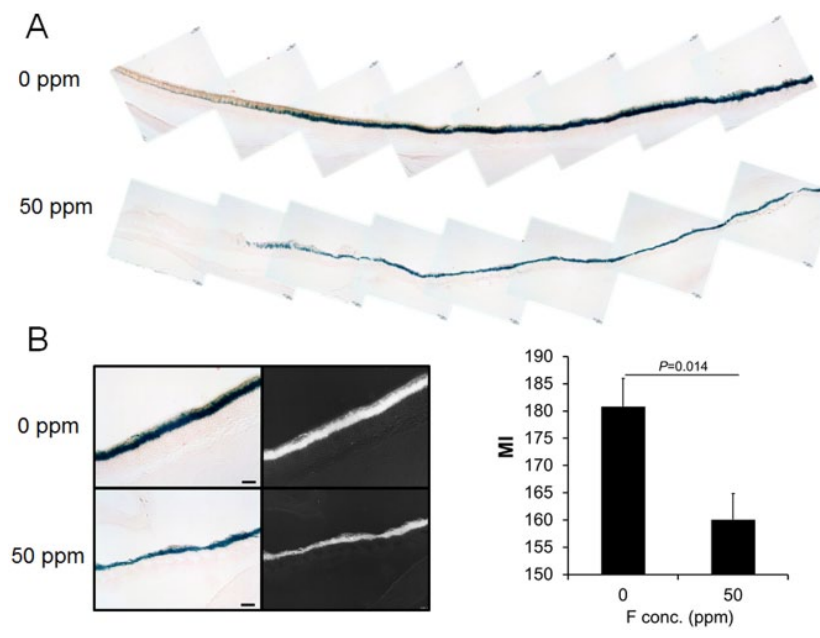

Figure 3. $K l k 4^{+/ L a c Z}$ knock-in mice had reduced LacZ expression after fluoride treatment. These knock-in mice have $1 \mathrm{Klk} 4$ allele with LacZ inserted in frame at the Klk4 translation initiation site. Therefore, the upstream promoter elements were identical for Klk4 and LacZ. The $K l k 4^{+/ L a c Z}$ mice were treated with fluoride $(0$ or $50 \mathrm{ppm})$ ad libitum in drinking water for $6 \mathrm{wk}$. (A) $\beta$-galactosidase histostaining of maxillary incisors from $\mathrm{Klk}^{+/ L a c Z}$ mice treated with 0 -ppm (upper panel) or 50-ppm (lower panel) fluoride. (B) High magnification of $\beta$-galactosidase staining (left panel) in maturation-stage ameloblasts after the indicated fluoride treatment. Bar represents $30 \mu \mathrm{m}$. Mean intensity (MI) as quantified by ImageJ analysis of $\beta$-galactosidase staining in maturationstage ameloblasts (right panel). Sections from 3 mice in each group were analyzed in duplicate, and representative images are shown. Data are expressed as mean $\pm \mathrm{SE}$.

promoter (Simmer et al., 2009). The knock-in LacZ has a nuclear localization signal to help distinguish its expression from endogenous lysosomal $\beta$-galactosidase. $\mathrm{F}^{-}$-treated $K l k 4^{+/ L a c Z}$ mouse maxillary incisors were stained with X-gal to quantify the level of LacZ expression. Staining was observed in ameloblast nuclei from the transition through maturation stages of development. Representative histostained cryosections of $K l k 4^{+/ L a c Z}$ are shown for control and $\mathrm{F}^{-}$-treated incisors (Fig. $3 \mathrm{~A})$, along with higher magnification images of nuclei staining (Fig. 3B, left panels). Mean intensity of staining was quantified 


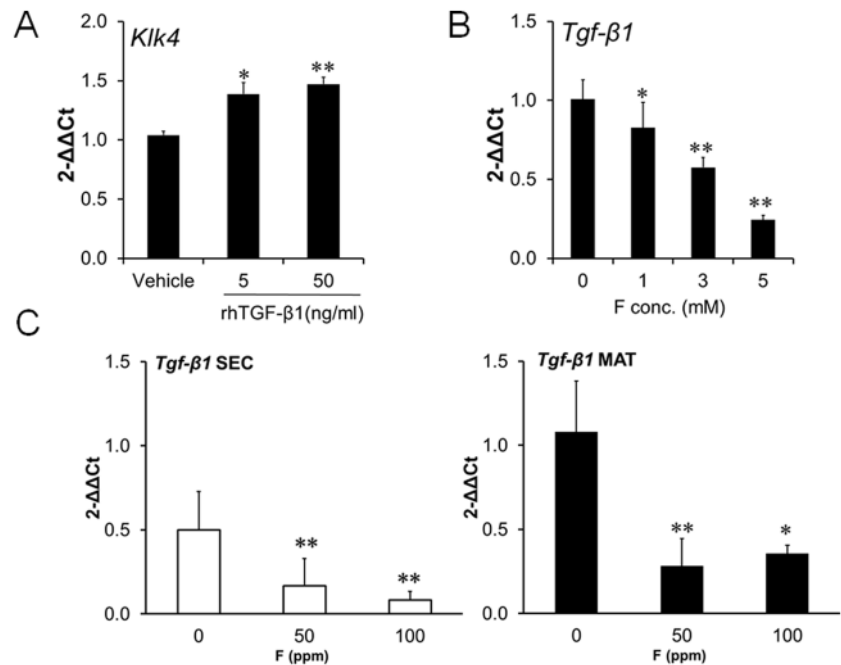

Figure 4. hrTGF- $\beta 1$ treatment increased KLK4 expression in human LNCaP cells, and fluoride decreased Tgf- $\beta 1$ expression in mouse ALC cells and in rat enamel organ. Gene expression was assessed by quantitative real-time polymerase chain reaction. (A) KLK4 expression in LNCaP cells treated for $24 \mathrm{hr}$ with either vehicle or hrTGF- $\beta 115$ and $50 \mathrm{ng} / \mathrm{mL}$ ). (B) Treatment of ALC cells with $0,1,3$, or $5 \mathrm{mM}$ fluoride as $\mathrm{NaF}$ for $24 \mathrm{hr}$ significantly reduced ALC Tgf- $\beta 1$ expression. (C) Tgf$\beta 1$ expression was significantly reduced in secretory-stage (SEC) and maturation-stage (MAT) rat enamel organ after treatment with fluoride $(0,50$, or $100 \mathrm{ppm})$ for $6 \mathrm{wk}$. Rn $18 \mathrm{~s}$ was the internal reference control gene for hrTGF- $\beta 1$ treatments, and Eefl $\alpha 1$ was the control gene for fluoride treatment. For the cell culture experiments, cDNA from 3 samples in each experimental treatment group were assayed 3 times in duplicate and data expressed as mean \pm SE (A and B). For the rat enamel organ experiments, cDNA from 4 rats in each treatment group were assayed in duplicate and data expressed as mean $\pm S D(C)$. ${ }^{*} p<.05,{ }^{* *} p<.01$, vs. control.

by use of ImageJ (Fig. 3B, graph). Mean intensity was significantly decreased with $\mathrm{F}^{-}$treatment $(0 \mathrm{ppm}, 181 \pm 5.2 ; 50 \mathrm{ppm}$, $160 \pm 4.8)$.

\section{TGF- $\beta 1$ Stimulates KLK4 Expression and Both Genes Are Downregulated by $\mathrm{F}^{-}$Exposure}

Previously, we reported that TGF- $\beta 1$ is upregulated in maturationstage EO. To determine if TGF- $\beta 1$ signaling upregulates $K L K 4$ expression, we treated $\mathrm{LNCaP}$ cells with human recombinant TGF- $\beta 1(0,5$, or $50 \mathrm{ng} / \mathrm{mL})$ for $24 \mathrm{hr}$. LNCaP cells were derived from a human prostatic adenocarcinoma, and they express KLK4. Human recombinant TGF- $\beta 1$ significantly increased LNCaP KLK4 transcript levels (Fig. 4A) indicating that KLK4 is regulated by TGF- $\beta 1$ signaling. Next, we asked if $\mathrm{F}^{-}$suppresses $T g f-\beta 1$ expression in ALCs or rat EO. ALCs were treated with the indicated $\mathrm{F}^{-}$concentrations for $24 \mathrm{hr}$, and subsequent $\mathrm{qPCR}$ results demonstrated that $T g f-\beta 1$ expression was significantly decreased (Fig. 4B). Consistent with previous data, $T g f-\beta 1$ expression significantly increased during the rat maturation stage compared with the secretory stage (Fig. 4C). $\mathrm{F}^{-}$treatment for $6 \mathrm{wk}$ significantly attenuated $T g f-\beta 1$ expression in both secretory- and maturation-stage rat EO (Fig. 4C). These data

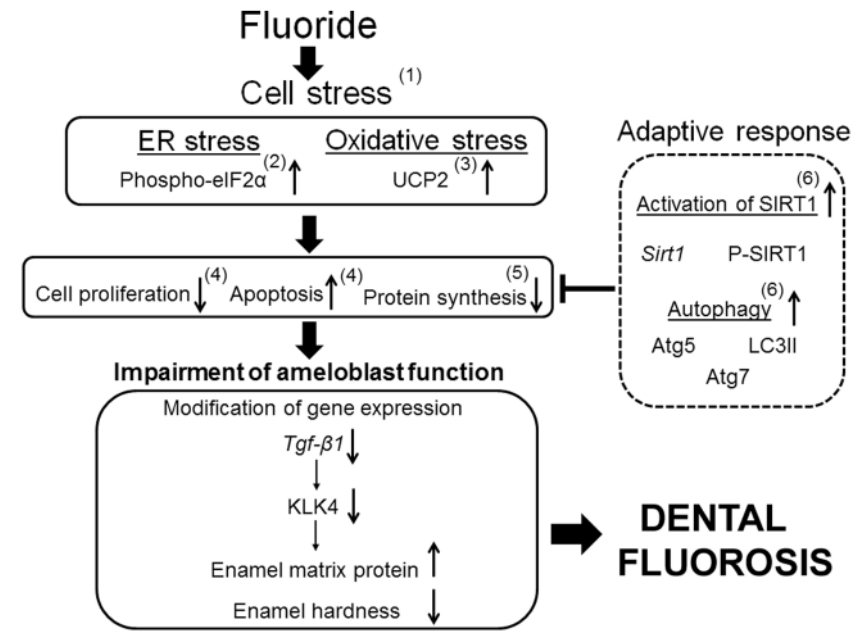

Figure 5. Presented is a schematic outlining our prior and current research results that characterize the mechanism of how fluoride causes dental fluorosis. Thick arrows indicate the progression of events leading to the impairment of ameloblast function. The sideways " $\mathrm{T}$ " indicates how activation of specific genes alleviate the toxic effects of fluoride-induced cell stress. Thin arrows indicate the direction of gene expression. (1) Cells. 1:631-645, 2012. (2) Environ Health Perspect. 116:1142-1146, 2008. (3) Connect Tiss Res. 55(Suppl 1):25-28, 2014. (4) J Biol Chem. 280:23194-23202, 2005. (5) PloS One. 5:e10895, 2010; Methods Enzymol. 491:111-125, 2011. (6) Biochim Biophys Acta. 842:245-255, 2014.

suggest that the $\mathrm{F}^{-}$-mediated downregulation of TGF- $\beta 1$ likely contributes to repressed KLK4 expression.

\section{DISCUSSION}

Here we demonstrate that $\mathrm{F}^{-}$downregulates Klk4 gene expression during the maturation stage but does not downregulate amelogenin or Mmp20 expression during the secretory stage of enamel development. We show that the $\mathrm{F}^{-}$-mediated Klk4 downregulation is reflected by an overall decrease in KLK4 protein within rat incisor enamel and that endogenous Klk4 promoterdriven LacZ expression is significantly reduced by $\mathrm{F}^{-}$exposure in mouse incisors. In contrast, during the secretory stage, amelogenin protein levels remained steady regardless of $\mathrm{F}^{-}$treatment. Furthermore, we show in vitro that TGF- $\beta 1$ induces KLK4 expression and that the presence of $\mathrm{F}^{-}$also significantly reduces $T g f-\beta 1$ expression. We confirm that $T g f-\beta 1$ is upregulated as rodent ameloblasts enter the maturation stage, and we demonstrate that $\mathrm{F}^{-}$significantly reduces $T g f-\beta 1$ expression during enamel development. Taken together, our data support the acid hypothesis stipulating that ameloblasts are more sensitive to the toxic effects of $\mathrm{F}^{-}$during the maturation stage when mass mineral precipitation occurs accompanied by mass proton release. Our data also suggest that $T g f-\beta 1$ is an important regulator of Klk4 expression. Figure 5 presents a summary of our current and prior data demonstrating that $\mathrm{F}^{-}$causes cell stress, that SIRT1 and autophagy alleviate $\mathrm{F}^{-}$-mediated cell stress, and that unresolved cell stress impairs ameloblast function. 
Supporting evidence that TGF- $\beta 1$ signaling promotes Klk4 expression was published using mice with amelogenin promoterdriven Cre recombinase and floxed $T g f-\beta$ receptor II. These mice had enamel with decreased mineral content and increased attrition, as well as thin enamel crystallites. Importantly, Klk4 mRNA levels were significantly reduced in these animals. It was concluded that TGF- $\beta$ signaling through the expression of Klk4 plays an important role in ameloblast function and in enamel maturation (Cho et al., 2013). The elevated expression of $T g f-\beta 1$ in mouse maturation-stage ameloblasts is accompanied by phosphorylation of Smad 2/3 (Tsuchiya et al., 2009). TGF- $\beta$ regulates Smad2/3-mediated downstream signaling, and Smad3-null mice had hypomineralized enamel (Yokozeki et al., 2003). Since ablation of Klk4 also results in hypomineralized enamel (Simmer et al., 2009), these studies provide compelling evidence suggesting that TGF- $\beta$ signaling in maturation-stage EO plays an important role in regulation of KLK4 expression during enamel development.

In contrast, Gao et al. (2009) showed that for ALCs, TGF- $\beta 1$ did not induce KLK4 expression but did induce MMP20 expression. In their study, MMP20 and KLK4 transcript levels were assessed by performing reverse transcription PCR with scanning of the resulting bands for quantification of gene expression. In an attempt to confirm their results, we did assess MMP20 and KLK4 expression in ALCs by use of quantitative real-time PCR, but we did not reach the cycle thresholds for MMP20 and KLK4 transcripts by our 35-cycle cutoff point. This is why we used the human prostate carcinoma cell line LNCaP, which expresses KLK4 (Xi et al., 2004), for our TGF- $\beta 1 /$ KLK4 expression-level studies.

Previously, we demonstrated that $\mathrm{F}^{-}$causes endoplasmic reticulum stress in ameloblasts responsible for enamel formation (Kubota et al., 2005); that $\mathrm{F}^{-}$-induced endoplasmic reticulum stress inhibits protein synthesis and secretion (Sharma et al., 2008); that, in the presence of $\mathrm{F}^{-}$, culture medium at a moderately low $\mathrm{pH}$ increases the level of the stress response (Sharma et al., 2010); and, recently, that Sirt1 and autophagy protect cells from $\mathrm{F}^{-}$-induced cell stress (Suzuki and Bartlett, 2014). Additionally, we have focused on determining if MMP20 or KLK4 plays a role in dental fluorosis. We showed that when wild-type and Mmp20 heterozygous mice were treated for $6 \mathrm{wk}$ with $\mathrm{F}^{-}$, mice with only 1 functional $\mathrm{Mmp} 20$ allele had enamel hardness values similar to wild-type enamel (Sharma et al., 2011). Strikingly, we performed exacting enzyme kinetics studies by use of Michaelis-Menten plots while recombinant enzymes were incubated with quenched fluorescent peptides to demonstrate that $\mathrm{F}^{-}$concentrations of up to $10 \mathrm{mM}$ had no effect on MMP20 or KLK4 enzymatic activity (Tye et al., 2011). Although KLK4 activity is not affected by $\mathrm{F}^{-}$treatment, its expression levels at both the mRNA level and the protein level are affected, which is likely why fluorosed enamel has a higher than normal protein content and is softer than normal. The significantly reduced KLK4 expression level precludes the ability to adequately cleave enamel matrix proteins so that they can be properly exported from the hardening enamel.

Since the acid hypothesis predicts that fluorosis caused by hydrofluoric acid will occur predominantly during the acidic maturation stage of enamel development, an unexpected result was that $\mathrm{F}^{-}$treatment reduced $T g f-\beta 1$ mRNA levels during the neutral secretory stage as well as during the acidic maturation stage. Expression levels of Mmp20 and amelogenin were not reduced by $\mathrm{F}^{-}$during the secretory stage, so it was surprising that this occurred for $T g f-\beta 1$. Perhaps, since TGF- $\beta 1$ can induce growth arrest or cell death (Siegel and Massagué, 2003), its expression is more easily reduced so that cells can better adapt to environmental stresses, such as $\mathrm{F}^{-}$exposure. However, when this occurs during the maturation stage of enamel development, a negative consequence may be that not enough KLK4 is expressed.

In conclusion, we demonstrate that $\mathrm{F}^{-}$decreases $K l k 4$ mRNA and protein levels in maturation-stage ameloblasts and in enamel, respectively. We also provide insight into a potential mechanism by which $\mathrm{F}^{-}$attenuates KLK4 expression through diminished TGF- $\beta 1$ signaling. These results suggest that downregulation of KLK4 by $\mathrm{F}^{-}$is one of the critical factors causing dental fluorosis.

\section{ACKNOWLEDGMENTS}

We thank Justine Dobeck for histology expertise and Dr. Toshihiro Sugiyama for generously providing us with ameloblast-lineage cells. The research reported in this publication was supported by the National Institute of Dental and Craniofacial Research of the National Institutes of Health under award numbers R01DE018106 and R01DE019775. The authors declare no potential conflicts of interest with respect to the authorship and/or publication of this article.

\section{REFERENCES}

Bartlett JD (2013). Dental enamel development: proteinases and their enamel matrix substrates. ISRN Dent 2013. Article ID 684607.

Centers for Disease Control and Prevention (2001). Recommendations for using fluoride to prevent and control dental caries in the United States. Morbidity and Mortality Weekly Report 50:1-42.

Cho A, Haruyama N, Hall B, Danton MJ, Zhang L, Arany P, et al. (2013). TGF-ss regulates enamel mineralization and maturation through KLK4 expression. PloS One 8:e82267.

Dean HT, Elvove E (1936). Some epidemiological aspects of chronic endemic dental fluorosis. Am J Public Health Nations Health 26:567-575.

DenBesten PK (1999). Biological mechanisms of dental fluorosis relevant to the use of fluoride supplements. Community Dent Oral Epidemiol 27:41-47.

Gao Y, Li D, Han T, Sun Y, Zhang J (2009). TGF-beta1 and TGFBR1 are expressed in ameloblasts and promote MMP20 expression. Anat Rec (Hoboken) 292:885-890.

Hu JC, Ryu OH, Chen JJ, Uchida T, Wakida K, Murakami C, et al. (2000). Localization of EMSP1 expression during tooth formation and cloning of mouse cDNA. J Dent Res 79:70-76.

$\mathrm{Hu}$ JC, Chun YH, Al Hazzazzi T, Simmer JP (2007). Enamel formation and amelogenesis imperfecta. Cells Tissues Organs 186:78-85.

Kubota K, Lee DH, Tsuchiya M, Young CS, Everett ET, Martinez-Mier EA, et al. (2005). Fluoride induces endoplasmic reticulum stress in ameloblasts responsible for dental enamel formation. J Biol Chem 280:2319423202.

Nakata A, Kameda T, Nagai H, Ikegami K, Duan Y, Terada K, et al. (2003). Establishment and characterization of a spontaneously immortalized mouse ameloblast-lineage cell line. Biochem Biophys Res Commun 308:834-839. 
Pfaffl MW (2001). A new mathematical model for relative quantification in real-time RT-PCR. Nucleic Acids Res 29:e45.

Ryu O, Hu JC, Yamakoshi Y, Villemain JL, Cao X, Zhang C, et al. (2002). Porcine kallikrein-4 activation, glycosylation, activity, and expression in prokaryotic and eukaryotic hosts. Eur J Oral Sci 110:358-365.

Schneider CA, Rasband WS, Eliceiri KW (2012). NIH Image to ImageJ: 25 years of image analysis. Nat Methods 9:671-675.

Sharma R, Tsuchiya M, Bartlett JD (2008). Fluoride induces endoplasmic reticulum stress and inhibits protein synthesis and secretion. Environ Health Perspect 116:1142-1146.

Sharma R, Tsuchiya M, Skobe Z, Tannous BA, Bartlett JD (2010). The acid test of fluoride: how pH modulates toxicity. PloS One 5:e10895.

Sharma R, Tye CE, Arun A, MacDonald D, Chatterjee A, Abrazinski T, et al. (2011). Assessment of dental fluorosis in Mmp20 +/- mice. J Dent Res 90:788-792.

Siegel PM, Massagué J (2003). Cytostatic and apoptotic actions of TGFbeta in homeostasis and cancer. Nat Rev Cancer 3:807-821.

Simmer JP, Fukae M, Tanabe T, Yamakoshi Y, Uchida T, Xue J, et al. (1998). Purification, characterization, and cloning of enamel matrix serine proteinase 1. J Dent Res 77:377-386.

Simmer JP, Hu Y, Lertlam R, Yamakoshi Y, Hu JC (2009). Hypomaturation enamel defects in Klk4 knockout/LacZ knockin mice. J Biol Chem 284:19110-19121.

Simmer JP, Richardson AS, Smith CE, Hu Y, Hu JC (2011). Expression of kallikrein-related peptidase 4 in dental and non-dental tissues. Eur $J$ Oral Sci 119(Suppl 1):226-233.

Simmer JP, Richardson AS, Hu YY, Smith CE, Ching-Chun Hu J (2012). A post-classical theory of enamel biomineralization ... and why we need one. Int J Oral Sci 4:129-134.
Smith CE, Richardson AS, Hu Y, Bartlett JD, Hu JC, Simmer JP (2011) Effect of kallikrein 4 loss on enamel mineralization: comparison with mice lacking matrix metalloproteinase 20. The J Biol Chem 286:1814918160.

Suzuki M, Bartlett JD (2014). Sirtuin1 and autophagy protect cells from fluoride-induced cell stress. Biochim Biophys Acta 1842:245-255.

Suzuki M, Sierant ML, Antone JV, Everett ET, Whitford GM, Bartlett JD (2014). Uncoupling protein-2 is an antioxidant that is up-regulated in the enamel organ of fluoride-treated rats. Connect Tiss Res 55(Suppl 1):25-28.

Tsuchiya M, Sharma R, Tye CE, Sugiyama T, Bartlett JD (2009). Transforming growth factor-beta1 expression is up-regulated in maturation-stage enamel organ and may induce ameloblast apoptosis. Eur $J$ Oral Sci 117:105-112.

Tung K, Fujita H, Yamashita Y, Takagi Y (2006). Effect of turpentineinduced fever during the enamel formation of rat incisor. Arch Oral Biol 51:464-470.

Tye CE, Antone JV, Bartlett JD (2011). Fluoride does not inhibit enamel protease activity. J Dent Res 90:489-494.

Xi Z, Klokk TI, Korkmaz K, Kurys P, Elbi C, Risberg B, et al. (2004). Kallikrein 4 is a predominantly nuclear protein and is overexpressed in prostate cancer. Cancer Res 64:2365-2370.

Yamakoshi Y, Yamakoshi F, Hu JC, Simmer JP (2011). Characterization of kallikrein-related peptidase 4 glycosylations. Eur J Oral Sci 119(Suppl 1):234-240.

Yokozeki M, Afanador E, Nishi M, Kaneko K, Shimokawa H, Yokote K, et al. (2003). Smad3 is required for enamel biomineralization. Biochem Biophys Res Commun 305:684-690.

Zanolli C, Bondioli L, Manni F, Rossi P, Macchiarelli R (2011). Gestation length, mode of delivery, and neonatal line-thickness variation. Hum Biol 83:695-713. 